\title{
Effects of Balance Control Training on Functional Outcomes in Subacute Hemiparetic Stroke Patients
}

\author{
Jin Seok Huh, $\mathrm{MD}^{1}$, Yang-Soo Lee, $\mathrm{MD}^{1}$, Chull-Hyun Kim, $\mathrm{MD}^{1}$, \\ Yu-Sun Min, $\mathrm{MD}^{2}$, Min-Gu Kang, $\mathrm{MD}^{2}$, Tae-Du Jung, $\mathrm{MD}^{1,2}$ \\ ${ }^{1}$ Department of Rehabilitation Medicine, Kyungpook National University College of Medicine, Daegu; \\ ${ }^{2}$ Department of Rehabilitation Medicine, Kyungpook National University Hospital, Daegu, Korea
}

Objective To investigate the efficacy of balance control training using a newly developed balance control trainer (BalPro) on the balance and gait of patients with subacute hemiparetic stroke.

Methods Forty-three subacute stroke patients were assigned to either a balance control training (BCT) group or a control group. The BCT group ( $\mathrm{n}=23)$ was trained with BalPro for 30 minutes a day, 5 days a week for 2 weeks, and received one daily session of conventional physical therapy. The control group $(n=20)$ received two sessions of conventional physical therapy every day for 2 weeks. The primary outcome was assessment with the Berg Balance Scale (BBS). Secondary outcomes were Functional Ambulation Category (FAC), the 6-minute walking test (6mWT), Timed Up and Go (TUG), the Korean version of Modified Barthel Index (K-MBI), and the manual muscle test (MMT) of the knee extensor. All outcome measures were evaluated before and after 2 weeks of training in both groups.

Results There were statistically significant improvements in all parameters except MMT and FAC after 2 weeks of treatment in both groups. After training, the BCT group showed greater improvements in the BBS and the 6mWT than did the control group.

Conclusion Balance control training using BalPro could be a useful treatment for improving balance and gait in subacute hemiparetic stroke patients.

Keywords Postural balance, Gait, Stroke

Received April 29, 2015; Accepted June 29, 2015

Corresponding author: Tae-Du Jung

Department of Rehabilitation Medicine, Kyungpook National University College of Medicine, 130 Dongdeok-ro, Jung-gu, Daegu 41944, Korea Tel: +82-53-200-5311, Fax: +82-53-423-0389, E-mail: teeed0522@hanmail.net

(c) This is an open-access article distributed under the terms of the Creative Commons Attribution Non-Commercial License (http://creativecommons. org/licenses/by-nc/4.0) which permits unrestricted noncommercial use, distribution, and reproduction in any medium, provided the original work is properly cited.

Copyright $\odot 2015$ by Korean Academy of Rehabilitation Medicine

\section{INTRODUCTION}

Hemiparetic stroke patients tend to have an asymmetric posture [1] and often exhibit an abnormal gait pattern or poor physical endurance. Many conventional treatments have been used to correct these issues [2-6].

Motor learning theory of Shumway-Cook and Woollacott [7] suggests that learning movement while simultaneously solving specific problems is effective. In 
general, horizontal movement and vertical movement of the center of mass (COM) are very important aspects of the human gait [8]. However, conventional rehabilitation methods focus mainly on horizontal movement; vertical movement is often ignored. In addition, such methods are not task-specific to gait or activities encountered in daily life $[3,9]$.

Therefore, our research team developed a new lower limb balance control trainer (BalPro; Man\&Tel, Gumi, Korea) that is capable of providing vertical movement as well as horizontal movement and task-oriented lower limb exercise. Lee et al. [10] showed that the balance control trainer, the previous version of the BalPro, was beneficial when used for chronic stroke patients who were somewhat able to stand and walk but had balance problems. They reported that balance and gait ability were improved after using the balance control trainer. Most of the improvement occurred within the first month, but the patients continued to improve for up to 6 months [11].

Based on these results, we predicted that balance control training using BalPro would also be effective for subacute stroke patients. If we are correct, the Berg Balance Scale (BBS), which measures the ability to balance, should show significant improvement after training. The 6-minute walking test (6mWT) and Timed Up and Go (TUG), which indicate temporal factors of mobility, may also significantly change. In the present study, we exam- ined the effects of BCT using BalPro on improving balance and gait ability in subacute stroke patients.

\section{MATERIALS AND METHODS}

\section{Participants and intervention}

Subacute stroke patients, 3-6 months after stroke occurrence, with fair or better knee extension strength were recruited. Patients with cognitive dysfunction (MiniMental State Examination <24), severe visual or perceptual impairments, lower limb musculoskeletal problems or defects, or a high risk of cardiac problems or other medical problems were excluded. Participants who were unable to perform three consecutive exercises or who could not participate in $80 \%$ or more of the total exercise sessions were also excluded. In total, 43 patients participated in the research.

Patients were randomly divided into two groups by flipping a coin. The balance control training (BCT) group received one session of conventional rehabilitation therapy and one session of BCT using BalPro daily. The control group received two sessions of conventional rehabilitation therapy every day. The BCT group received each therapy for 30 minutes per day, 5 days a week, for 2 weeks. BCT using BalPro consisted of 10 minutes of weight shifting and knee flexion exercises, moving a cursor on a screen, and 20 minutes of playing a fruit-har-

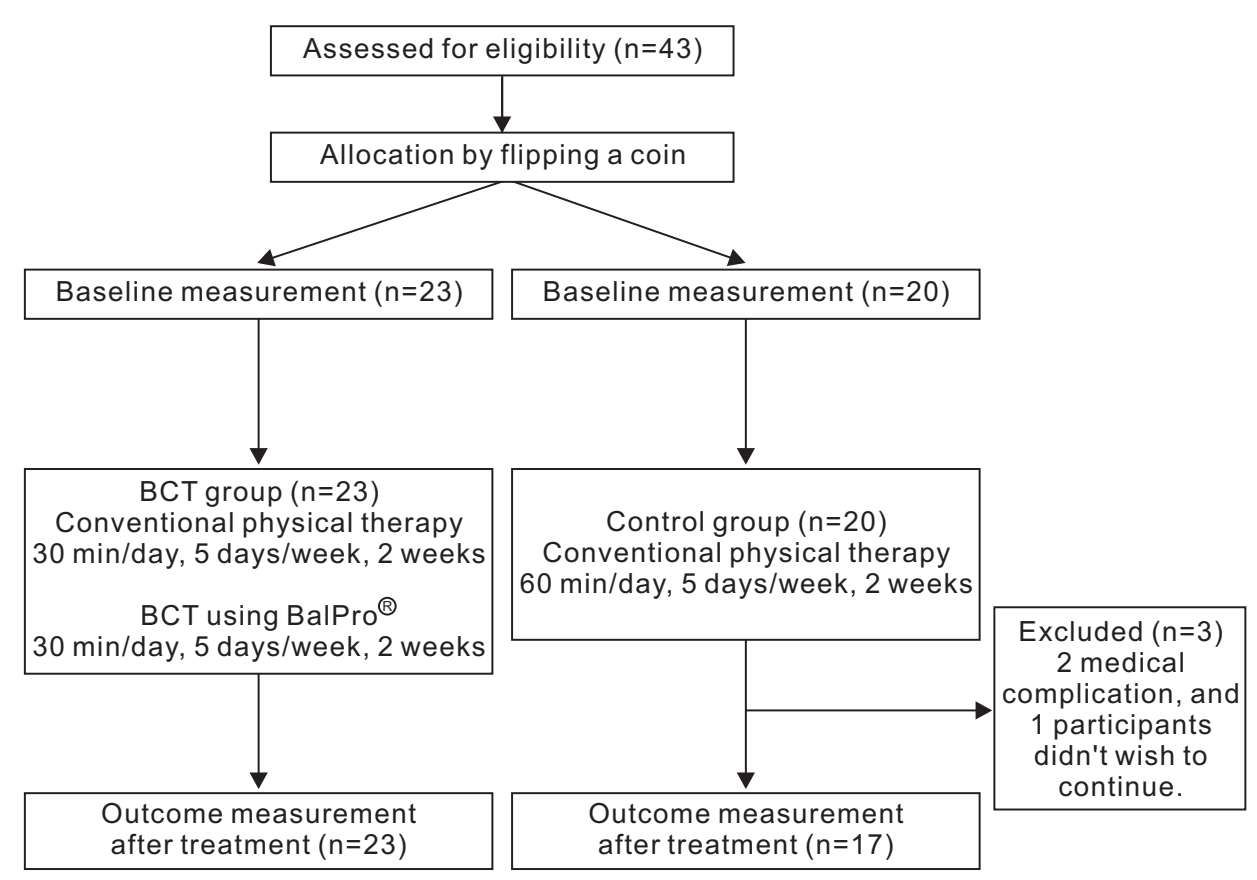

Fig. 1. Flow diagram of this study. In total, 43 patients participated in the research. Patients were randomly divided into two groups by flipping a coin. Three participants from the control group did not complete the study due to medical complications $(n=2)$ or personal reasons $(\mathrm{n}=1)$. 
vesting game, which requires repetitive horizontal weight shifting and knee joint movement for visual feedback. The control group received two 30 -minute sessions of conventional therapy per day, 5 days a week, for 2 weeks. To ensure the same amount of exercise, both groups were kept from additional therapy or bedside exercises. Both groups had their balance and gait ability evaluated at admission and after 2 weeks of treatment (Fig. 1).

The study was conducted according to the Declaration of Helsinki and in keeping with local regulations. The study was performed with the approval of the Institutional Review Board of Kyungpook National University (No. 2014-01-019-001). Written informed consent was obtained from all participants.

\section{Balance control trainer}

We used the BalPro (Man\&Tel), a commercially available lower limb rehabilitation machine. It consists of a balance board, which can sense horizontal shifts in weight; a tilting sensor, which can sense knee joint angle; a computer system, including game software that processes incoming movement data; and a screen to help with visual feedback. To prevent patients from falling down, harnesses and a safety bar were used. Pressure sensors in the balance board process the patient's pressure center and the software translates it into a horizontal cursor movement on the screen. A tilting sensor placed on the lateral side of the knee processes knee joint movement and the software translates it into a vertical cursor movement on the screen. By moving a hand-shaped cursor on the screen, patients are able to 'pick' fruit in a fruit-harvesting electronic game. The game changes the scenery and type of fruit every time a patient finishes picking fruit (Fig. 2).

\section{Outcome measures}

BBS was the primary outcome measure. BBS has been shown to yield valid data that have excellent intra-rater and inter-rater reliability; this scale is widely used as an outcome measure for balance performance [12]. Functional Ambulation Category (FAC), 6mWT, TUG, the Korean version of Modified Barthel Index (K-MBI), and the manual muscle test (MMT) were used as secondary outcome measures to evaluate participants' functional ability. MMT was used to assess knee extension strength. All assessments were performed initially and after 2 weeks of treatment.

\section{Statistical analysis}

For statistical analysis, SPSS version 12.0 for Microsoft Windows was used. The chi-square and independent sample t-test were used to assess the pre-exercise difference between the two groups. The paired sample t-test was used to compare each group's pre-exercise and postexercise data. The independent sample t-test was used to compare the two groups after treatment. A p-value less than 0.05 was considered statistically significant.

\section{RESULTS}

\section{General characteristics of patients}

The BCT group consisted of 16 males and 7 females and the control group consisted of 10 males and 7 females. The average age of the BCT group was $69.51 \pm 0.92$ years and that of the control group was $60.87 \pm 6.12$ years, which was not a significant difference. The mean time from stroke occurrence was $4.10 \pm 1.25$ months for the BCT group and 4.13 \pm 1.31 months for the control group (no significant difference). Lesion area and etiology also showed no significant difference between the two groups. There were no statistically significant differences between the two groups as assessed by the BBS, FAC,

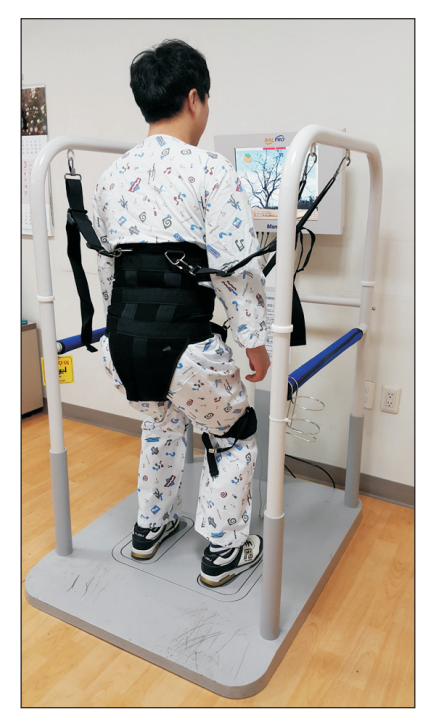

Fig. 2. BalPro (Man\&Tel, Gumi, Korea) consists of a balance board, a tilting sensor, a computer system, and a screen. To prevent patients from falling down, a harness and a safety bar are used. 
6mWT, TUG, K-MBI, or MMT prior to treatment (Table 1). All 23 participants in the BCT group completed the

Table 1. Demographic data of subjects

\begin{tabular}{lcc}
\hline \multicolumn{1}{c}{ Variable } & $\begin{array}{c}\text { BCT group } \\
(\mathbf{n = 2 3 )}\end{array}$ & $\begin{array}{c}\text { Control group } \\
(\mathbf{n = 1 7 )}\end{array}$ \\
\hline Sex & & \\
\hline Male & $16(70.0)$ & $10(59.0)$ \\
\hline Female & $7(30.0)$ & $7(41.0)$ \\
Age (yr) & $69.51 \pm 0.92$ & $60.87 \pm 6.12$ \\
\hline Duration (mo) & $4.10 \pm 1.25$ & $4.13 \pm 1.31$ \\
Affected side & & \\
\hline Right & $10(43.0)$ & $8(47.0)$ \\
\hline Left & $13(57.0)$ & $9(53.0)$ \\
Type & & \\
\hline Infarction & $13(57.0)$ & $9(53.0)$ \\
\hline Hemorrhage & $10(43.0)$ & $8(47.0)$ \\
\hline BBS & $37.25 \pm 5.74$ & $38.69 \pm 4.69$ \\
\hline FAC & $3.05 \pm 0.76$ & $3.19 \pm 0.66$ \\
\hline 6mWT (s) & $56.90 \pm 19.59$ & $58.44 \pm 16.09$ \\
\hline TUG (s) & $17.75 \pm 6.23$ & $17.00 \pm 5.29$ \\
\hline K-MBI & $71.35 \pm 11.71$ & $73.00 \pm 9.78$ \\
\hline MMT & $3.15 \pm 0.75$ & $3.25 \pm 0.68$ \\
\hline
\end{tabular}

Values are presented as means \pm standard deviation or number (\%).

BCT, balance control training; BBS, Berg Balance Scale; FAC, Functional Ambulation Category; 6mWT, 6-minute walking test; TUG, Timed Up and Go test; K-MBI, Korean version of Modified Barthel Index; MMT, manual muscle test. program. However, 3 participants from the control group did not complete the study due to medical complications $(n=2)$ or personal reasons $(n=1)$ (Fig. 1$)$.

\section{Training effects}

After 2 weeks of therapy, both groups showed a statistically significant improvement in the BBS, $6 \mathrm{mWT}$, TUG, and K-MBI. However, the BCT group showed greater statistical improvements in both the BBS and the 6mWT. The change in BBS score was $7.05 \pm 3.80$ in the BCT group and 3.69 \pm 2.41 in the control group. The change in the $6 \mathrm{mWT}$ was $12.25 \pm 5.62 \mathrm{~m}$ in the BCT group and $8.19 \pm 3.94$ $m$ in the control group $(\mathrm{p}<0.05)$ (Table 2$)$.

\section{DISCUSSION}

This prospective study showed that BCT using BalPro can achieve greater improvements in balance and gait ability, compared to conventional therapy, in subacute stroke patients.

Balance consists of steadiness, symmetry, and dynamic stability. Steadiness refers to the ability to maintain a given posture. Symmetry is used to describe equal weight distribution, and dynamic stability is the ability to move within a given posture [13]. All of these components of balance are disturbed following stroke [14]. The role of the brain in post-stroke gait ability is not properly understood [15]. Eighty percent of post-stroke patients show asymmetric and unstable gait. Problems such as decreased weight bearing of the hemiparetic leg

Table 2. Changes in clinical parameters in the BCT group and the control group

\begin{tabular}{lcccccc}
\hline & \multicolumn{3}{c}{ BCT group (n=23) } & \multicolumn{3}{c}{ Control group (n=17) } \\
\cline { 2 - 7 } & Initial & Follow-up & $\Delta$ & Initial & Follow-up & $\Delta$ \\
\hline BBS & $37.25 \pm 5.74$ & $44.30 \pm 6.63^{\text {a) }}$ & $7.05 \pm 3.80^{\text {b) }}$ & $38.69 \pm 4.69$ & $42.38 \pm 4.86^{\text {a) }}$ & $3.69 \pm 2.41^{\text {b) }}$ \\
FAC & $3.05 \pm 0.76$ & $3.20 \pm 0.70$ & $0.15 \pm 0.58$ & $3.19 \pm 0.66$ & $3.31 \pm 0.48$ & $0.13 \pm 0.34$ \\
6mWT (m) & $56.90 \pm 19.59$ & $69.15 \pm 20.66^{\text {a) }}$ & $12.25 \pm 5.62^{\text {b) }}$ & $58.44 \pm 16.09$ & $66.62 \pm 15.68^{\text {a) }}$ & $8.19 \pm 3.94^{\text {b) }}$ \\
TUG (s) & $17.75 \pm 6.23$ & $13.95 \pm 4.98^{\text {a) }}$ & $3.80 \pm 2.07$ & $17.00 \pm 5.29$ & $14.43 \pm 3.86^{\text {a) }}$ & $2.56 \pm 2.56$ \\
K-MBI & $71.35 \pm 11.71$ & $79.35 \pm 10.40^{\text {a) }}$ & $8.00 \pm 3.73$ & $73.00 \pm 9.78$ & $80.38 \pm 7.88^{\text {a) }}$ & $7.38 \pm 5.74$ \\
MMT & $3.15 \pm 0.75$ & $3.35 \pm 0.59$ & $0.20 \pm 0.41$ & $3.25 \pm 0.68$ & $3.43 \pm 0.51$ & $0.19 \pm 0.40$ \\
\hline
\end{tabular}

Values are presented as mean \pm standard deviation.

BCT, balance control training; BBS, Berg Balance Scale; FAC, Functional Ambulation Category; 6mWT, 6-minute walking test; TUG, Timed Up and Go test; K-MBI, Korean version of Modified Barthel Index; MMT, manual muscle test.

a) $<<0.05$, significant difference pre-exercise vs. post-exercise.

${ }^{b)} \mathrm{p}<0.05$, significant difference between groups. 
or asymmetric body weight distribution are common in post-stroke hemiparetic patients. Furthermore, several previous studies demonstrated moderate relationships between balance function and gait speed, independence, dressing, wheelchair mobility, reaching, and quality of life [16-19]. Because hemiparetic stroke-related deficits have negative effects on motor function and affect daily life, BCT is thought to be helpful in improving not only balance but also other functional abilities in stroke patients $[7,20]$. Many conventional treatments such as neurodevelopmental training and sensory stimulation have been performed to help patients shift their weight to the affected side. But these treatments focus solely on horizontal movement and are not task-specific [3,9]. More recent studies have focused on achieving better movement capability through various weight-shifting exercises and task-specific treatments [21,22].

Lai et al. [23] and Morone et al. [24] reported that, compared to conventional therapy, therapy that includes a video game (i.e., that uses visual stimulation and a foot pad) can lead to greater improvement in the BBS, $6 \mathrm{mWT}$, TUG, Modified Falls Efficacy Scale, and unipedal stance test. Nichols [25] and Betker et al. [26] reported that balance training with visual feedback achieved higher participation and compliance, a lower incidence of falls, and a lower center of mass amplitude. However, the evidence concerning visual feedback training using a balance board to improve functional movement is scarce and controversial $[14,27,28]$.

Treadmill training with body weight support is a taskspecific approach for improving gait in hemiplegic patients [2]. Other weight-shifting exercises use machines such as weight-unloading devices, robots, and balancetraining systems like the Balance Master System [4$6,12,29]$. Despite their potential therapeutic efficacy, these treatment methods have yet to demonstrate sufficient cost-effectiveness. In addition, the outcomes of these types of training are still under debate. For example, Barclay-Goddard et al. [30] showed that the Balance Master System failed to improve BBS or TUG scores while the patient is moving or walking. The reason for these debates seems to be that these treatments only address horizontal movement.

Minimizing the change in the body's center of gravity, vertically as well as horizontally, is the major mechanism for saving energy during walking [8]. In addition, vertical body movement is the key factor in standing up, which is an essential movement in maintenance of gait and daily life [31-33]. Therefore, training for vertical movement is important in improving an individual's gait.

We considered these crucial elements of functional movement in the design of a new balance control trainer called BalPro. BalPro considers both vertical and horizontal movement of the COM during gait, thus overcoming the limitations of the balance master system [34]. In addition, it is a task-specific exercise that uses visual feedback. To ensure the safety of users, a harness system and a safety bar are used during exercise. In the present study, no patients dropped out of the BCT group and no adverse effects were observed during the training period with BalPro.

As expected, there were statistically significant improvements in clinical parameters such as the BBS, $6 \mathrm{mWT}$, TUG, and K-MBI over 2 weeks of treatment in both the BCT group and the control (conventional physical therapy only) group. However, there were no significant differences in improvement of FAC and MMT of the knee extensor. A treatment period of 2 weeks seems to be too short for FAC and MMT scores to improve significantly. The BCT group showed significantly higher improvement on the BBS and the $6 \mathrm{mWT}$ than did the control group.

The $6 \mathrm{mWT}$ is a standardized test of functional exercise capacity that is increasingly used to assess mobility [35]. As discussed, the vertical movement of the COM is an essential component of gait [8]. The BBS measures a subject's ability to maintain balance while performing functional tasks. These tasks involve vertical movement such as standing from a sitting position, sitting from a standing position, and transferring oneself from one place to another [36]. Thus, the more significant improvement seen in the BCT group is probably attributable to improvements in vertical movement.

Although the difference was not statistically significant, TUG, which assesses gait from a sitting position, also showed slightly higher improvement in the BCT group. A longer treatment period could have led to a statistically significant improvement.

Our results indicate that BCT using BalPro is an improved treatment option for balance and gait ability in subacute stroke patients. In addition, this treatment provides increased motivation for exercise because conventional exercises are often repetitive, causing patients 
to lose interest and fail to complete the rehabilitation process [37].

This study had some limitations. First, it was impossible to blind the experimental testing as participants knew they had undergone BCT training. Second, we did not include any information regarding treatments used in the acute stages of stroke rehabilitation. However, the groups did not show any statistically significant differences preintervention. Third, the therapy period was only 2 weeks long. The final limitation is the small number of participants. Further studies that overcome these limitations and classify post-stroke recovery based on the effects of individual therapies are needed. In addition, the relationship between region or etiology of brain injury and usefulness of a lower limb balance trainer should be studied.

In conclusion, BCT using BalPro shows promise for improving balance and gait in subacute stroke patients who are unable to ambulate independently.

\section{CONFLICT OF INTEREST}

No potential conflict of interest relevant to this article was reported.

\section{ACKNOWLEDGMENTS}

This work was supported by a Biomedical Research Institute grant, Kyungpook National University Hospital in 2013.

\section{REFERENCES}

1. Brandstater ME, de Bruin H, Gowland C, Clark BM. Hemiplegic gait: analysis of temporal variables. Arch Phys Med Rehabil 1983;64:583-7.

2. Moseley AM, Stark A, Cameron ID, Pollock A. Treadmill training and body weight support for walking after stroke. Cochrane Database Syst Rev 2005;(4):CD002840.

3. Lorish TR, Sandin KJ, Roth EJ, Noll SF. Stroke rehabilitation. 3: Rehabilitation evaluation and management. Arch Phys Med Rehabil 1994;75(5 Spec No):S47-51.

4. Patton J, Brown DA, Peshkin M, Santos-Munne JJ, Makhlin A, Lewis E, et al. KineAssist: design and development of a robotic overground gait and balance therapy device. Top Stroke Rehabil 2008;15:131-9.

5. Mayr A, Kofler M, Quirbach E, Matzak H, Frohlich K, Saltuari L. Prospective, blinded, randomized crossover study of gait rehabilitation in stroke patients using the Lokomat gait orthosis. Neurorehabil Neural Repair 2007;21:307-14.

6. Husemann B, Muller F, Krewer C, Heller S, Koenig E. Effects of locomotion training with assistance of a robot-driven gait orthosis in hemiparetic patients after stroke: a randomized controlled pilot study. Stroke 2007;38:349-54.

7. Shumway-Cook A, Woollacott MH. Motor control: translating research into clinical practice. 3rd ed. Philadelphia: Lippincott Williams \& Wilkins; 2007. p. 3-83.

8. Perry J, Burnfield JM. Gait analysis: normal and pathological function. 2nd ed. Thorofare: Slack Inc.; 2010.

9. Bobath B. Adult hemiplegia: evaluation and treatment. 3rd ed. London: Butterworth-Heinemann; 1990. p. 70-160.

10. Lee SH, Byun SD, Kim CH, Go JY, Nam HU, Huh JS, et al. Feasibility and effects of newly developed balance control trainer for mobility and balance in chronic stroke patients: a randomized controlled trial. Ann Rehabil Med 2012;36:521-9.

11. Bonita R, Beaglehole R. Recovery of motor function after stroke. Stroke 1988;19:1497-500.

12. Liston RA, Brouwer BJ. Reliability and validity of measures obtained from stroke patients using the Balance Master. Arch Phys Med Rehabil 1996;77:425-30.

13. Goldie PA, Bach TM, Evans OM. Force platform measures for evaluating postural control: reliability and validity. Arch Phys Med Rehabil 1989;70:510-7.

14. Dickstein R, Nissan M, Pillar T, Scheer D. Foot-ground pressure pattern of standing hemiplegic patients: major characteristics and patterns of improvement. Phys Ther 1984;64:19-23.

15. Verma R, Arya KN, Sharma P, Garg RK. Understanding gait control in post-stroke: implications for management. J Bodyw Mov Ther 2012;16:14-21.

16. Bohannon RW. Gait performance of hemiparetic stroke patients: selected variables. Arch Phys Med Rehabil 1987;68:777-81.

17. Nichols DS, Miller L, Colby LA, Pease WS. Sitting balance: its relation to function in individuals with hemiparesis. Arch Phys Med Rehabil 1996;77:865-9. 
18. Fishman MN, Nichols DS, Colby I.A, Sachs L. Comparison of functional upper extremity tasks and dynamic standing balance in hemiparesis. Phys Ther 1996;76:S79.

19. Schmid AA, Van Puymbroeck M, Altenburger PA, Miller KK, Combs SA, Page SJ. Balance is associated with quality of life in chronic stroke. Top Stroke Rehabil 2013;20:340-6.

20. Winstein CJ. Knowledge of results and motor learning: implications for physical therapy. Phys Ther 1991;71:140-9.

21. de Haart M, Geurts AC, Dault MC, Nienhuis B, Duysens J. Restoration of weight-shifting capacity in patients with postacute stroke: a rehabilitation cohort study. Arch Phys Med Rehabil 2005;86:755-62.

22. Richards CL, Malouin F, Wood-Dauphinee S, Williams JI, Bouchard JP, Brunet D. Task-specific physical therapy for optimization of gait recovery in acute stroke patients. Arch Phys Med Rehabil 1993;74:612-20.

23. Lai CH, Peng CW, Chen YL, Huang CP, Hsiao YL, Chen SC. Effects of interactive video-game based system exercise on the balance of the elderly. Gait Posture 2013;37:511-5.

24. Morone G, Tramontano M, Iosa M, Shofany J, Iemma A, Musicco M, et al. The efficacy of balance training with video game-based therapy in subacute stroke patients: a randomized controlled trial. Biomed Res Int 2014;2014:580861.

25. Nichols DS. Balance retraining after stroke using force platform biofeedback. Phys Ther 1997;77:553-8.

26. Betker AL, Szturm T, Moussavi ZK, Nett C. Video game-based exercises for balance rehabilitation: a single-subject design. Arch Phys Med Rehabil 2006;87: 1141-9.

27. Winstein CJ, Gardner ER, McNeal DR, Barto PS, Nicholson DE. Standing balance training: effect on balance and locomotion in hemiparetic adults. Arch Phys Med Rehabil 1989;70:755-62.

28. Geiger RA, Allen JB, O'Keefe J, Hicks RR. Balance and mobility following stroke: effects of physical therapy interventions with and without biofeedback/forceplate training. Phys Ther 2001;81:995-1005.

29. Hesse S, Bertelt C, Jahnke MT, Schaffrin A, Baake P, Malezic M, et al. Treadmill training with partial body weight support compared with physiotherapy in nonambulatory hemiparetic patients. Stroke 1995;26:97681.

30. Barclay-Goddard R, Stevenson T, Poluha W, Moffatt ME, Taback SP. Force platform feedback for standing balance training after stroke. Cochrane Database Syst Rev 2004;(4):CD004129.

31. Lee MY, Wong MK, Tang FT, Cheng PT, Lin PS. Comparison of balance responses and motor patterns during sit-to-stand task with functional mobility in stroke patients. Am J Phys Med Rehabil 1997;76:401-10.

32. Cheng PT, Liaw MY, Wong MK, Tang FT, Lee MY, Lin PS. The sit-to-stand movement in stroke patients and its correlation with falling. Arch Phys Med Rehabil 1998;79:1043-6.

33. Vander Linden DW, Brunt D, McCulloch MU. Variant and invariant characteristics of the sit-to-stand task in healthy elderly adults. Arch Phys Med Rehabil 1994;75:653-60.

34. Byun SD, Jung TD, Kim CH, Lee YS. Effects of the sliding rehabilitation machine on balance and gait in chronic stroke patients: a controlled clinical trial. Clin Rehabil 2011;25:408-15.

35. Rasekaba T, Lee AL, Naughton MT, Williams TJ, Holland AE. The six-minute walk test: a useful metric for the cardiopulmonary patient. Intern Med J 2009;39: 495-501.

36. Kornetti DL, Fritz SL, Chiu YP, Light KE, Velozo CA. Rating scale analysis of the Berg Balance Scale. Arch Phys Med Rehabil 2004;85:1128-35.

37. Studenski S, Perera S, Hile E, Keller V, Spadola-Bogard J, Garcia J. Interactive video dance games for healthy older adults. J Nutr Health Aging 2010;14:850-2. 